\title{
Competition mechanism of interfacial cracks in thermal barrier coating system
}

DOI:

10.1016/j.matdes.2017.07.018

\section{Document Version}

Accepted author manuscript

Link to publication record in Manchester Research Explorer

\section{Citation for published version (APA):}

Jiang, P., Fan, X., Sun, Y., Li, D., Li, B., \& Wang, T. (2017). Competition mechanism of interfacial cracks in thermal barrier coating system. Materials and Design, 132, 559-566. https://doi.org/10.1016/j.matdes.2017.07.018

\section{Published in:}

Materials and Design

\section{Citing this paper}

Please note that where the full-text provided on Manchester Research Explorer is the Author Accepted Manuscript or Proof version this may differ from the final Published version. If citing, it is advised that you check and use the publisher's definitive version.

\section{General rights}

Copyright and moral rights for the publications made accessible in the Research Explorer are retained by the authors and/or other copyright owners and it is a condition of accessing publications that users recognise and abide by the legal requirements associated with these rights.

\section{Takedown policy}

If you believe that this document breaches copyright please refer to the University of Manchester's Takedown Procedures [http://man.ac.uk/04Y6Bo] or contact uml.scholarlycommunications@manchester.ac.uk providing relevant details, so we can investigate your claim.

\section{OPEN ACCESS}




\section{Accepted Manuscript}

Competition mechanism of interfacial cracks in thermal barrier coating system

Peng Jiang, Xueling Fan, Yongle Sun, Dingjun Li, Biao Li, Tiejun Wang

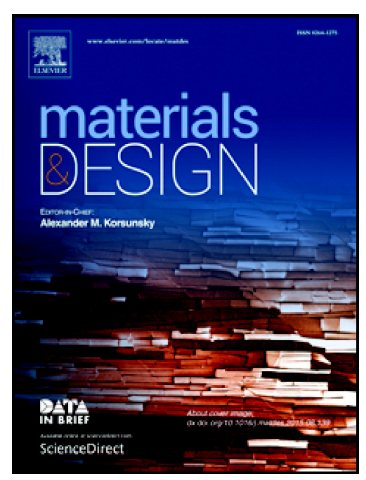

PII: S0264-1275(17)30679-2

DOI: doi: 10.1016/j.matdes.2017.07.018

Reference: JMADE 3208

To appear in: Materials \& Design

Received date: $\quad 4$ March 2017

Revised date: $\quad 10$ May 2017

Accepted date: $\quad 10$ July 2017

Please cite this article as: Peng Jiang, Xueling Fan, Yongle Sun, Dingjun Li, Biao Li, Tiejun Wang, Competition mechanism of interfacial cracks in thermal barrier coating system, Materials \& Design (2017), doi: 10.1016/j.matdes.2017.07.018

This is a PDF file of an unedited manuscript that has been accepted for publication. As a service to our customers we are providing this early version of the manuscript. The manuscript will undergo copyediting, typesetting, and review of the resulting proof before it is published in its final form. Please note that during the production process errors may be discovered which could affect the content, and all legal disclaimers that apply to the journal pertain. 


\title{
Competition mechanism of interfacial cracks in thermal barrier coating system
}

\author{
Peng Jiang ${ }^{\mathrm{a}}$, Xueling Fan ${ }^{\mathrm{a},{ }^{*}}$, Yongle Sun ${ }^{\mathrm{b}}$, Dingjun $\mathrm{Li}^{\mathrm{a}}$, Biao Li ${ }^{\mathrm{a}}$, Tiejun Wang ${ }^{\mathrm{a},{ }^{*}}$
}

${ }^{\text {a }}$ State Key Laboratory for Strength and Vibration of Mechanical Structures, School of Aerospace Engineering, Xi'an Jiaotong University, Xi'an, 710049, China

${ }^{\mathrm{b}}$ School of Mechanical, Aerospace and Civil Engineering, Dalton Nuclear Institute, The University of Manchester, Sackville Street, Manchester M13 9PL, UK

*Corresponding author: Prof. Xueling Fan

State Key Laboratory for Strength and Vibration of Mechanical Structures

School of Aerospace Engineering

Xi'an Jiaotong University

No. 28 Xianning West Road

Xi'an, Shaanxi, 710049, P.R. China

TEL: +86-29-82667864

FAX: +86-29-82669044

E-mail: fanxueling@mail.xjtu.edu.cn

E-mails for other authors:

Peng Jiang: dmfuture@stu.xjtu.edu.cn

Yongle Sun: yongle.sun@manchester.ac.uk

Dingjun Li: lidingjun@ mail.dfstw.com

Biao Li: libiao@mail.xjtu.edu.cn

Tiejun Wang: 973wtj@xjtu.edu.cn 


\begin{abstract}
:
The mechanism of competition between different interfacial cracks is investigated, specifically considering the cracks at top-coat/bond-coat and bond-coat/substrate interfaces in a thermal barrier coating system (TBCs). To assess the cracking process driven by mechanical loading, in-situ three-point bending tests were conducted on TBCs samples having different top coats (TC) and bond coats (BC). The competition between cracks at $\mathrm{TC} / \mathrm{BC}$ and $\mathrm{BC} /$ substrate interfaces was observed for the first time, and then analyzed to elucidate the mechanism. Experimental and numerical results show that the differences in modulus ratio and thickness ratio of $\mathrm{TC}$ to $\mathrm{BC}$ are the main factors controlling the competition, which eventually leads to different fracture modes, i.e. when TC thickness is large or BC modulus is low, the coatings peel off from the TC/BC interface; while, with the decreasing TC thickness or increasing $\mathrm{BC}$ modulus, the delamination location changes to $\mathrm{BC} /$ substrate interface. A failure map based on the two ratios is numerically established, which agrees well with the experimental results. It is advised that the crack propagation path can be controlled by adjusting the combination of the two ratios to trigger both $\mathrm{TC} / \mathrm{BC}$ and $\mathrm{BC} /$ substrate interfacial cracks in TBCs, thereby leading to more energy dissipation and better bending-resistance.
\end{abstract}

Keywords: Thermal barrier coating; interfacial crack; competition mechanism; fracture mode; failure map 


\section{Introduction}

Thermal barrier coating system (TBCs) has been widely used for enhancing the performance of advanced gas turbines in key industrial fields (e.g. energy and transport), due to their excellent thermal insulation properties and durability. A typical TBCs consists of ceramic top coat (TC), thermally grown oxide (TGO, a thin layer formed due to oxidation), bond coat (BC) and substrate (Sub) [1-4]. Cracks often initiate and grow in the coatings or at the interfaces between different layers due to the stresses produced in service [5-7]. Such cracks accelerate the premature failure in adhesion of coatings, which have limited the reliabilities and durability of TBCs [8-11]. Therefore, it is important to have a good understanding on their failure mechanism. Issues about cracks in TBCs during service were investigated extensively in previous studies, with consideration of different influence factors. Erdogan and Schulze $[12,13]$ investigated the effect of periodic surface cracks on the interfacial fracture behaviors. Chen et al. [14] found different failure modes in TBCs with bond coat deposited by different spraying methods. Fan et al. $[6,15,16]$ analyzed the influence of crack length, and other physical and material parameters on the driving force of multiple surface cracking in film systems. Fang et al. [17] experimentally studied the effect of top ceramic coat thickness on spallation of TBCs. Chen et al. [18] presented an analytical model to study the influence of geometric parameters on fracture characteristic of coating system. Bumgardner et al. [19] studied the wear and indentation damage mechanism of TBCs during its operational lifecycle, in which a coupled imaging and contact model analyses was adopted to identify the location and time of delamination and its underlying causes. Sun et al. [20] investigated the initiation of interfacial cracks considering the creep of thermally grown oxide by theoretical and numerical analyses. Xu et al. [7] conducted a systematic calculation of geometric factors affecting the crack driving forces at interfaces to study the interfacial delamination of TBCs. More recently, Bumgardner et al. [21] investigated the high-temperature delamination mechanism of dense vertically cracked TBCs via a combination of in-situ digital image correlation and finite element analyses, showing the coupled formation mechanisms of vertical and horizontal cracks during thermal cycling up to $1200{ }^{\circ} \mathrm{C}$.

Although the thermal stress is the main reason for the failure of TBCs during service, three-point bending test is a common method to evaluate the production quality and load-bearing 
capacity of as-sprayed TBCs before service, as well as for understanding the fracture process occurring in ceramic coatings [22-24]. Despite the wide practical use, the three-point bending based evaluation method lacks solid theoretical or numerical basis, and the results are often interpreted with specific experience. This requires a better understanding of failure mechanism of TBCs under three-point bending to guide the further design. In the crack problems of TBCs under three-point bending, the path of crack propagation directly determines the fracture modes. Fig. 1 shows the schematics of crack path selection. Due to the mechanical bending, vertical cracks often initiate first at the surface of top coat. One crack can easily penetrate across the top-coat, but then be arrested at the top-coat/bond-coat (TC/BC) interface. Afterwards, the crack propagation has two potential paths, i.e. along interface and in vertical direction. It is clear that there is a competition between the crack deflection along TC/BC interface and the continuous penetration into BC, as shown in Fig. 1a. If the crack deflects along TC/BC interface, as shown in Fig. 1b, the top coat will peel off from this interface when neighboring interfacial cracks converge. If the crack further penetrates into $\mathrm{BC}$, it will propagate across $\mathrm{BC}$ and then be temporarily inhibited by $\mathrm{BC} / \mathrm{Sub}$ interface. This leads to another competition between two interfacial cracks, as depicted in Fig. 1c. The competition will result in two distinctive fracture modes: (i) cracks propagate and eventually fracture at $\mathrm{TC} / \mathrm{BC}$ interface (see Fig. 1d); (ii) cracks propagate at $\mathrm{BC} / \mathrm{Sub}$ interface and ultimately separate at this interface (see Fig. 1e).

The competition of crack deflection/penetration at an interface (Figs. 1a and 1b) was first recognized and analyzed by Cook [25] and then others [26-30]. In these previous studies, linear-elastic fracture mechanics was usually employed to establish the critical condition based on strength and energy. Of particular note is the work by Parmigiania [30] for a bi-material system, in which the determination whether crack deflection or penetration occurs was examined by using a cohesive-zone model incorporating both strength and toughness parameters. Failure mechanism maps considering the ratio of substrate toughness to interface toughness, and the ratio of substrate strength to interface strength, were also given by Parmigiania [30]. 


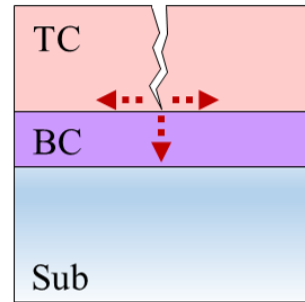

Competition of deflection/penetration

(a)

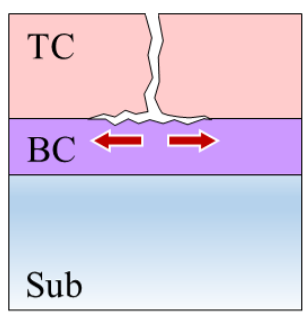

Peeling off from $\mathrm{TC} / \mathrm{BC}$ interface

(b)

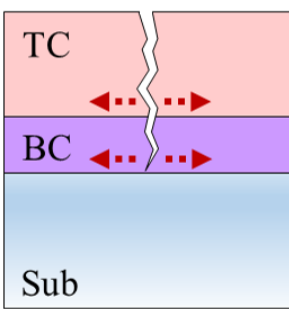

Competition of interfacial cracks

(c)

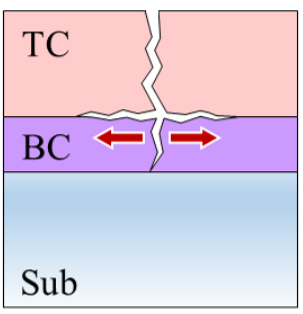

Separation from

$\mathrm{TC} / \mathrm{BC}$ interface

(d)

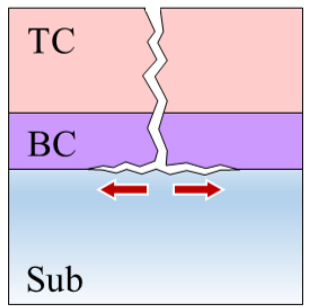

Fracture at

$\mathrm{BC} / \mathrm{Sub}$ interface

(e)

Fig. 1. Schematics showing the selection of crack propagation path: (a) competition of crack deflection and penetration; (b) crack deflects along TC/BC interface and the coating peels off from $\mathrm{TC} / \mathrm{BC}$ interface (c) crack penetrates into $\mathrm{BC}$ and is arrested at $\mathrm{BC} / \mathrm{Sub}$ interface, which leads to a competition of cracks at TC/BC and BC/Sub interfaces; (d) crack propagates at TC/BC interface; (e) crack propagates at $\mathrm{BC} / \mathrm{Sub}$ interface.

Although Figs. 1c-1e depicts a potential competition of interfacial cracks in TBCs, it still lacks experimental evidence and good understanding of the underlying mechanism. Nucleation, propagation and convergence of horizontal cracks at different interfaces in TBCs can also generate different fracture modes, depending on specific cracking process. In the present work, competition mechanism of $\mathrm{TC} / \mathrm{BC}$ and $\mathrm{BC} / \mathrm{Sub}$ interfacial cracks in $\mathrm{TBCs}$ under three-point bending, considering the effects of TC-to-BC thickness ratio and modulus ratio, is investigated by experimental and numerical analyses. This paper is organized as follows. In Section 2, the sample preparation of TBCs and the experimental setup of in-situ three-point bending test are described. In Section 3, an experimental observation of competition phenomenon between $\mathrm{TB} / \mathrm{BC}$ and $\mathrm{BC} / \mathrm{Sub}$ interfacial cracks is presented, and two typical fracture modes are demonstrated and 
discussed with respect to different top coats and bond coats. An image of typical competition phenomenon between interfacial cracks at top-coat/bond-coat and bond-coat/substrate interfaces is captured. In Section 4, numerical analysis on the competition mechanism of TC/BC and BC/Sub interfacial cracks is carried out, and furthermore, a failure map based on thickness ratio and modulus ratio between top coat and bond coat is given, which agrees with experimental results well. In Section 5, concluding remarks are drawn.

\section{Material and experimental method}

\subsection{TBCs sample preparation}

The substrate of the TBCs studied herein was made of nickel-based superalloy IN718 (40 $\mathrm{mm} \times 7 \mathrm{~mm} \times 1.5 \mathrm{~mm})$. Commercial NiCoCrAlY powders $(45 \sim 75 \mu \mathrm{m}, \mathrm{Ni}: 32 \mathrm{wt} \%$, Co:38.5wt $\%$, Cr:21wt $\%$, Al:8wt $\%$, Y:0.5wt $\%$, Sulze-Metco) were used for spraying BC. Commercial YSZ powders (45 100 $\mu \mathrm{m}$, purity 99.99\%, Institute of Process Engineering, Chinese Academy of Science) were used for spraying TC. Two groups of TBCs samples were prepared. For group I, air plasma spraying (APS) or high velocity oxygen fuel spraying (HVOF) was employed to deposit a $\mathrm{BC}$ with a thickness of $150 \mu \mathrm{m}$ onto the superalloy substrate, and APS was employed to fabricate a TC with a thickness of $300 \mu \mathrm{m}$. For group II, TC was prepared by APS and two values of thickness, i.e. $300 \mu \mathrm{m}$ and $600 \mu \mathrm{m}$, were considered, and a $150 \mu \mathrm{m}$ thick BC was deposited by HVOF. The APS setting was METCO 9MB (Oerlikon Metco, Swiss) and the HVOF equipment was Praxair JP-8000 (Praxair Technology, Inc., USA). Before the spraying of bond coat, the substrates were grit blasted by 46 mesh size aluminum oxide particles. Then the substrate was sprayed either by APS or by HVOF with the same bond coat powder. The grit blasting was carried out using a high-pressure suction blasting system (STELLE, China. Model: STR-1212). The surface roughness average of blasted substrate was measured as $4.5 \sim 5.5 \mu \mathrm{m}$ using a surface roughness tester (Mitutoyo, Japan. Model: SJ-310). The surface of bond coat was not grit blasted before the spraying of top coat, and the roughness was measured as $4 \sim 5 \mu \mathrm{m}$. Detailed thermal spray parameters used are listed in Table 1. 
Table 1. Detailed thermal spray parameters of bond coat and top coat.

\begin{tabular}{cccc}
\hline Parameters & APS for BC & HVOF for BC & APS for TC \\
\hline Gun & METCO F4 & Praxair JP-8000 & METCO F4 \\
Power $(\mathrm{KW})$ & 42.2 & - & 33.8 \\
Distance (mm) & 100 & 380 & 120 \\
Ar/H $(\mathrm{SLPM})$ & $55 / 6.5$ & - & $35 / 6.5$ \\
Feed Rate $(\mathrm{g} / \mathrm{min})$ & 45 & 60 & 40 \\
Gun velocity (mm/s) & 400 & 700 & 500 \\
Fuel $(\mathrm{GPH})$ & - & 6.5 & - \\
Oxygen $(\mathrm{SCPH})$ & - & 2100 & - \\
Carrier gas (NLPM) & - & 23 & - \\
\hline
\end{tabular}

\subsection{In-situ three-point bending test}

A three-point bending rig (DEBEN, MICROTEST 2000) integrated in a scanning electron microscope (SEM, FEI QUANTA 400) was employed to in-situ assess the fracture behavior of the TBCs during loading. In the bending rig, the upper rollers were fixed, and the lower roller was moved in a speed of $0.5 \mathrm{~mm} / \mathrm{min}$ to apply the load. The span between two fixed rollers was 30 mm. Displacement $(D)$ of the moving roller was recorded with built-in displacement sensor. Fig. 2 shows the detail of the experimental setup. During the bending testing, the nucleation, deflection, propagation and convergence of vertical and interfacial cracks were imaged dynamically, see typical image shown in Fig. 2b. Before testing, cross-sections of all samples were ground, polished and carefully cleaned by ultrasonic oscillator. Three samples were tested for each kind of TBCs to obtain the average data. 


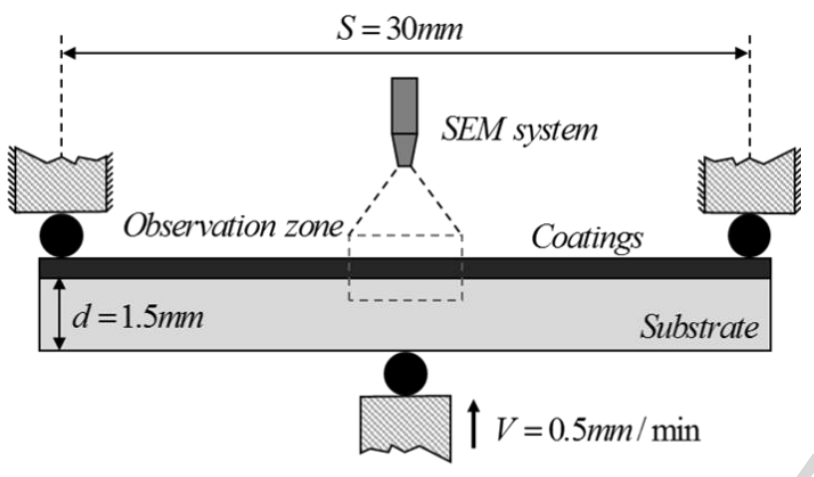

(a)

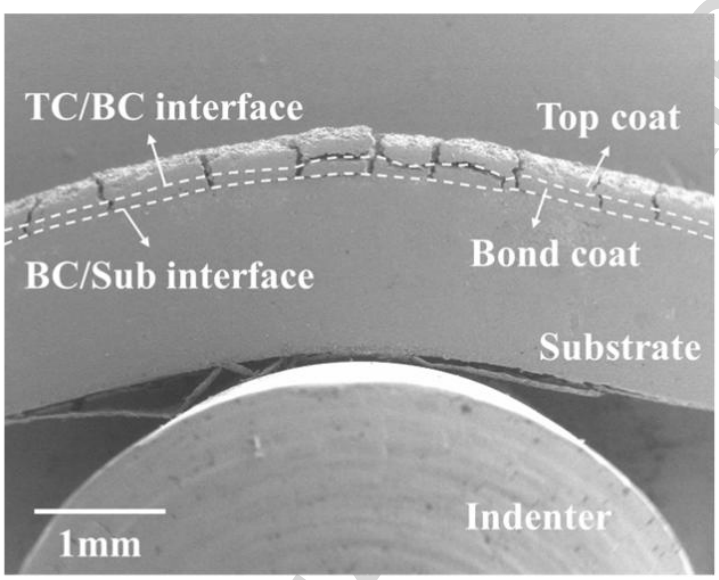

(b)

Fig. 2. (a) Schematic diagram of three-point bending setup, and (b) in-situ observation of cross-sections of TBCs sample with cracks.

\section{Experimental results}

Fig. 3 shows the different fracture modes (observed from the cross-section SEM image) of TBCs samples in group I, of which BC was sprayed by different fabrication methods. It can be seen that the coatings broke into many small segments with a length of about $400 \mu \mathrm{m} \sim 700 \mu \mathrm{m}$. For the TBCs sample with BC sprayed by APS (Fig. 3a), both the TC/BC and BC/Sub interfacial cracks occur in one coating segment bounded by two neighboring vertical cracks. The TC/BC interfacial cracks are evidently much longer than the $\mathrm{BC} / \mathrm{Sub}$ interfacial cracks, so the coating eventually fractured at TC/BC interface when the loading displacement of middle roller reached about $9.45 \mathrm{~mm}$, which caused a large area spallation of the top coat. No delamination occurred at BC/Sub interface. For the TBCs sample with BC sprayed by HVOF (Fig. 3b), both TC/BC and $\mathrm{BC} / \mathrm{Sub}$ interfacial cracks formed, but the coating eventually separated from $\mathrm{BC} / \mathrm{Sub}$ interface when the loading displacement of middle roller reached about $9.52 \mathrm{~mm}$. The fracture modes 
identified from the SEM images of typical samples for the two kinds of TBCs with BC deposited by different spraying methods (Figs. 3a and 3b) have been also confirmed by the observations of other samples. In addition, according to Figs. $3 a$ and $3 b$, different fracture modes occurred at similar loading displacement, which is similar to the experiment result reported by Chen et al. [14]. It is the different spaying methods (i.e. APS and HVOF) used to fabricate BC in the group I samples that mainly affect the competition between the TC/BC and BC/Sub interfacial cracks, as well as the resulting distinctive fracture modes.
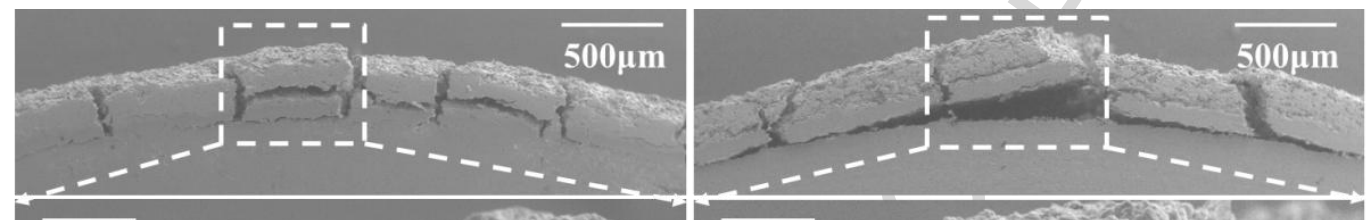

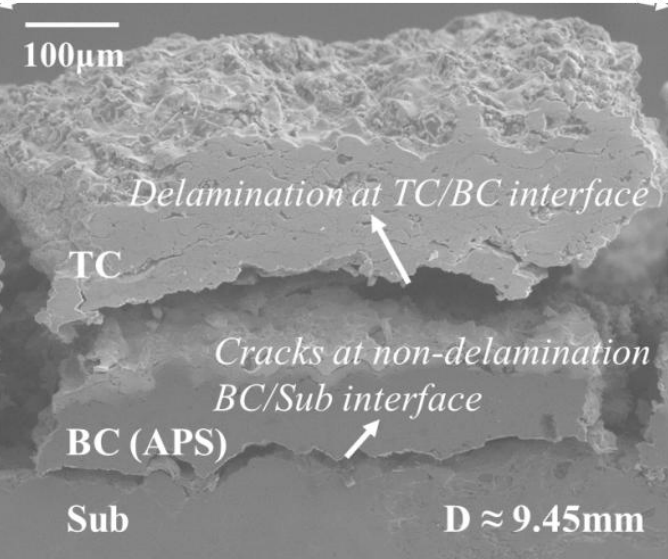

(a)

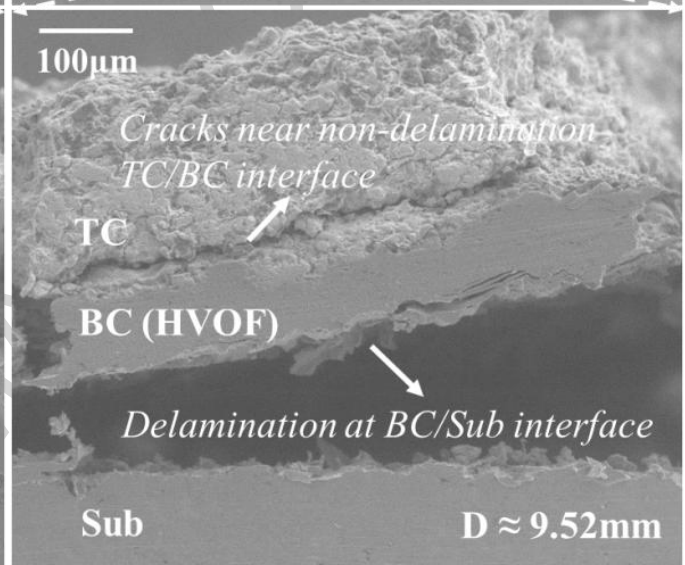

(b)

Fig. 3. SEM images of group I samples, showing different fracture modes due to the different spraying methods of BC used: (a) TBCs sample with BC sprayed by APS eventually fractured at TC/BC interface (b) TBCs sample with BC sprayed by HVOF eventually separated from BC/Sub interface.

The SEM images showing the effects of TC thickness on the fracture mode, for TBCs samples in group II, are presented in Fig. 4. Coating segments with a length of about $600 \mu \mathrm{m} \sim$ $800 \mu \mathrm{m}$ are formed in all the samples tested. It is clearly seen that vertical cracks initiated from the surface of TC and penetrated into BC, thereby producing the segments. Fig. 4a shows that, for the TBCs sample with $600 \mu \mathrm{m}$ TC and $150 \mu \mathrm{m} \mathrm{BC}$, interfacial crack at TC/BC interface dominates the fracture behavior of TBCs, leading to a final separation from TC/BC interface at a loading displacement of about $8.37 \mathrm{~mm}$, while BC/Sub interface was almost not damaged. Fig. 4b shows that, for the TBCs sample with $300 \mu \mathrm{m}$ TC and $150 \mu \mathrm{m} \mathrm{BC}$, the crack deflection occurred at $\mathrm{BC} / \mathrm{Sub}$ interface, while the $\mathrm{TC} / \mathrm{BC}$ interface remained intact. This resulted in the ultimate 
delamination of the segments encompassing both $\mathrm{TC}$ and $\mathrm{BC}$ at a loading displacement of about $9.52 \mathrm{~mm}$. From Fig. 4, it is clearly seen that different fracture modes of the group II samples developed, mainly due to the different thicknesses of TC considered. It also demonstrates the competition between $\mathrm{TC} / \mathrm{BC}$ and $\mathrm{BC} / \mathrm{Sub}$ interfacial cracks.

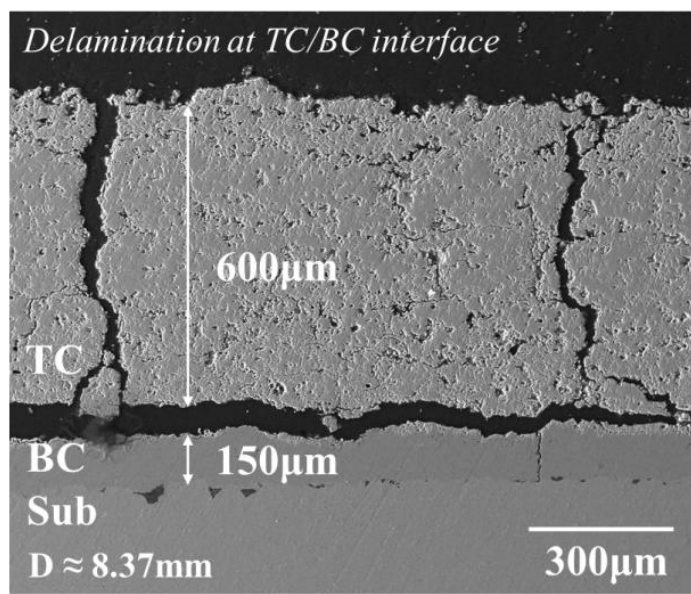

(a)

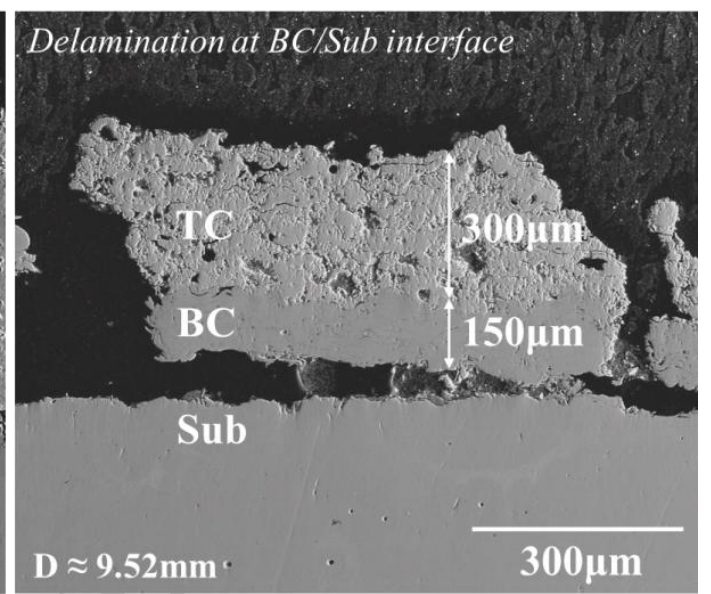

(b)

Fig. 4. SEM images of group II showing different fracture modes due to the different thicknesses of TC considered: (a) TBCs sample with thicker TC peeled off from TC/BC interface (b) TBCs sample with thinner TC peeled off from BC/Sub interface.

The distinctive fracture modes of different TBCs samples have been shown in Figs. 3 and 4. It is also important to understand the development process of these fracture modes. Fig. 5 shows a typical competition phenomenon between $\mathrm{TC} / \mathrm{BC}$ and $\mathrm{BC} / \mathrm{Sub}$ interfacial cracks during the cracking process, which was observed for the first time to the best of the authors' knowledge. It can be seen that when the loading displacement of the middle roller is about $3.85 \mathrm{~mm}$ (less than half of the final failure displacement), two main vertical cracks developed and split the coatings, resulting in an isolated segment. At the same time, many micro interfacial cracks initiated and propagated at both $\mathrm{TC} / \mathrm{BC}$ and $\mathrm{BC} / \mathrm{Sub}$ interfaces. This experimental evidence proves the existence of the competition between the two kinds of interfacial cracks. Common experience shows that the difference in spraying method of BC lead to the significant discrepancy of BC's modulus, and thus causes the modulus mismatch between TC and BC. Our experimental results also show the dependence of fracture modes on the TC thickness. It is thus believed that the two non-dimensional parameters, i.e. modulus ratio and thickness ratio between $\mathrm{TC}$ and $\mathrm{BC}$, both 
affect the competition of interfacial cracks in TBCs. Also, the spraying methods of BC (APS and HVOF) may lead to some difference in the bonding strength of $\mathrm{BC} / \mathrm{Sub}$ interface, but the influence on the fracture mode can be ignored. If the failure mode is significantly affected by the difference of bonding strength caused by spraying method, the TBCs sample with HVOF sprayed $\mathrm{BC}$ will be more likely to separate from TC/BC interface, because the HVOF method may lead to a higher bonding strength of $\mathrm{BC} / \mathrm{Sub}$ interface. But the experimental results in Fig. 3 show that the TBCs sample with HVOF sprayed BC is more likely to failure at $\mathrm{BC} / \mathrm{Sub}$ interface, which demonstrates that the effect of the difference in interfacial bonding strength caused by spraying method is not obvious when compared with the modulus.

To examine and extend the understanding established from experimental observations, a numerical analysis was carried out, which was validated by the experimental data and provided more details for elucidating the completion mechanism and the critical boundary between two fracture modes, as presented in Section 4.

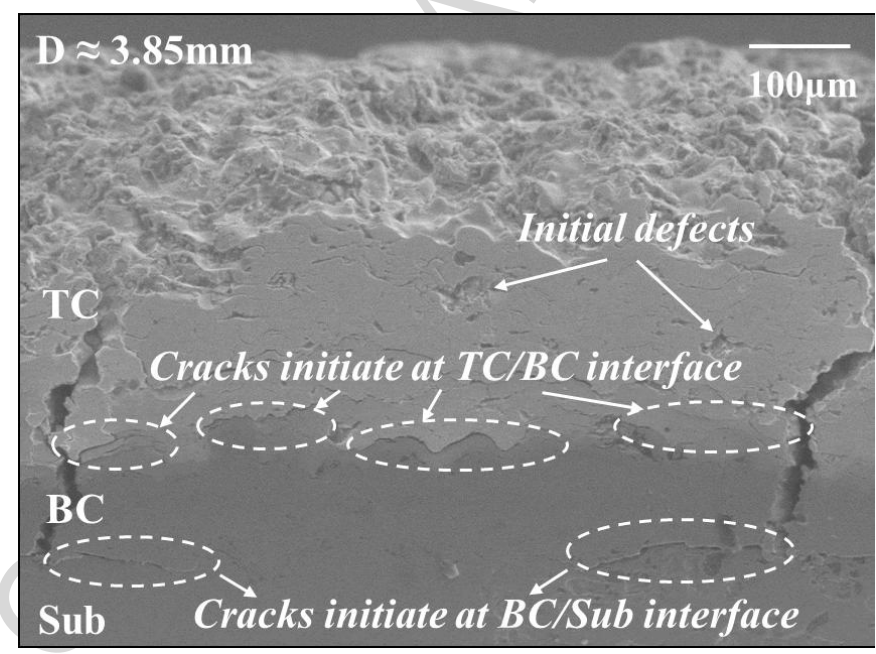

Fig. 5. SEM images showing the typical competition phenomenon between TC/BC and BC/Sub interfacial cracks in TBCs under three-point bending.

\section{Finite element analysis}

\subsection{Numerical model}

A two dimensional, plane strain model was constructed based on the commercial FEM code ABAQUS. Fig. 6a shows a TBCs model with vertical cracks penetrating from top surface of TC to the $\mathrm{BC} / \mathrm{Sub}$ interface, which was used to simulate the competition between TC/BC and $\mathrm{BC} / \mathrm{Sub}$ interfacial cracks. Owing to symmetry, only a segment in the middle of the sample was considered. 
As illustrated in Fig. 6b, the FE model includes three layers, i.e. TC, BC, substrate, and two interfaces, i.e. TC/BC interface and BC/Sub interface. The length of the considered segment is 600 $\mu \mathrm{m}$, simplified from the experimental observation (Figs. 3 and 4). The thicknesses of the BC and substrate are $150 \mu \mathrm{m}$ and $1.5 \mathrm{~mm}$, respectively. A bending moment was applied to the ends of the substrate of the segment, which was generated by a boundary condition with linear displacement gradient from TC/BC interface to the bottom of substrate. Competition of interfacial cracks can be triggered under the bending introduced by the substrate deformation. According to the experimental results, the ratio of maximum displacement at $\mathrm{BC} / \mathrm{Sub}$ interface to the length of the segment was chosen to be $7 \%$. Stress free boundary conditions were applied on other surfaces. It should be noted that the residual stress, which can be largely released by the vertical cracks, and the thermally grown oxide, which is formed mainly during service, were not considered in the FE simulation.

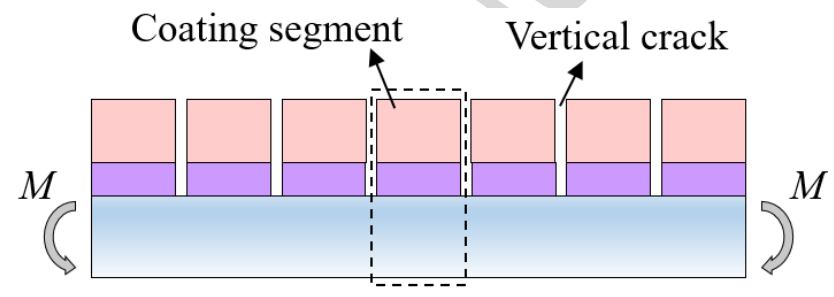

(a)

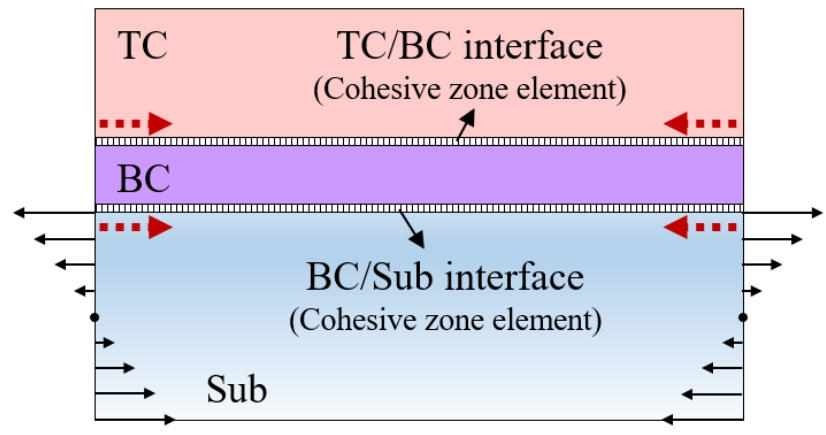

(b)

Fig. 6. (a) Illustration of the geometry of TBCs with multiple vertical cracks before the competition of interfacial cracks (b) a segment analyzed in finite element simulation.

TC, BC and substrate were all meshed with four-node bilinear plane strain quadrilateral reduced integration elements (CPE4R). TC and BC were considered as isotropic, homogeneous and linear elastic materials. The Young's modulus and Poisson's ratio of TC was $40 \mathrm{GPa}$ and 0.22 [31], respectively. The Poisson's ratio of BC was set as 0.3 . The substrate was assumed to be elastic-plastic with linear hardening, whose constitutive relationships are given by [24] 


$$
\sigma=\left\{\begin{array}{ll}
E_{s} \varepsilon, & \varepsilon \leq \frac{\sigma_{y}}{E_{s}} \\
\sigma_{y}+E_{s}^{*}\left(\varepsilon-\frac{\sigma_{y}}{E_{s}}\right), & \varepsilon>\frac{\sigma_{y}}{E_{s}}
\end{array},\right.
$$

where $\sigma$ and $\varepsilon$ are the stress and the strain of the substrate, respectively, $\sigma_{y}$ is the yield strength and was set as $850 \mathrm{MPa}[24], E_{s}$ is the Young's modulus (130 GPa [32]), $E_{s}^{*}$ is the hardening modulus which was taken as $10 \%$ of the Young's modulus, and the Poisson's ratio is 0.3 [24].

Cohesive zone model (CZM) based on traction-separation law was employed to simulate the initiation and propagation of interfacial cracks. The CZM has its origins from Dugdale [33] and has been widely used in numerical simulation schemes [6, 34]. Herein, a bilinear traction-separation law was adopted, as shown in Fig. 7. The traction across the cohesive zone plane increases with displacement up to a maximum cohesive strength, causing the initiation of damage in the cohesive element. Then, the traction gradually decreases. Once the area under the traction-separation curve is equal to the interfacial fracture toughness, $\Gamma_{n, s}$, or the critical separation, $\delta_{n, s}^{c}$, is reached, the traction decays to zero, and the cohesive element is assumed to fail completely, leading to the propagation of the crack. Note that $n$ and $s$ represent the normal and shear direction, respectively. In the traction-separation law, the slope before damage initiation is defined as interfacial stiffness, $K_{n, s}$. There are two main parameters controlling the fracture behavior of cohesive element - a characteristic toughness (the area under the curve), $\Gamma_{n, s}$, and a characteristic strength (closely related to the cohesive strength for many traction-separation laws), $\sigma_{n, s}^{c}$.

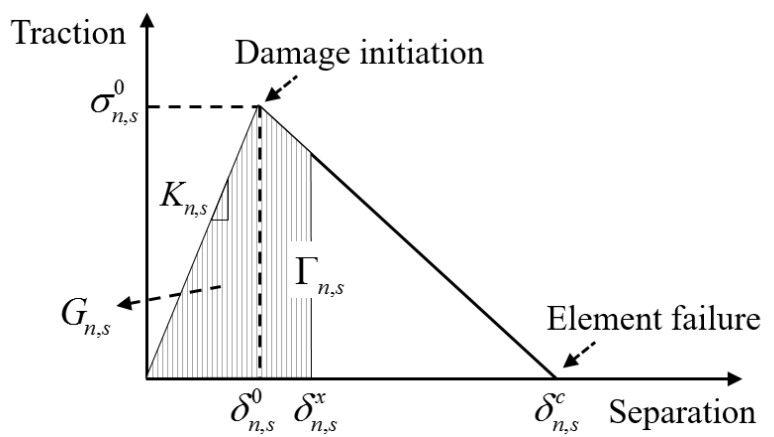

Fig. 7. A bilinear traction-separation law used in the cohesive zone model. 
When it comes to the mixed-mode fracture, the damage initiation criterion of pure tension and pure shear modes need to be coupled [35]

$$
\left(\frac{\left\langle\sigma_{n}\right\rangle}{\sigma_{n}^{0}}\right)^{2}+\left(\frac{\sigma_{s}}{\sigma_{s}^{0}}\right)^{2}=1,
$$

where the symbol $<>$ represents the Macaulay bracket that can be represented as

$$
\left\langle\sigma_{n}\right\rangle=\left\{\begin{array}{ll}
\sigma_{n}, & \sigma_{n} \geq 0 \\
0, & \sigma_{n}<0
\end{array} .\right.
$$

The power exponential criterion [36] was employed to describe the mixed mode fracture,

$$
\left(\frac{G_{n}}{\Gamma_{n}}\right)^{\alpha}+\left(\frac{G_{s}}{\Gamma_{s}}\right)^{\alpha}=1,
$$

where $G_{n}$ is the mode-I energy-release rate, $\Gamma_{n}$ is the mode-I toughness, $G_{s}$ is the mode-II energy release rate, and $\Gamma_{s}$ is the mode-II toughness. The exponent $\alpha$ was chosen as 1 . In this formulation, the toughness is defined as the total area under the traction-separation curve, and the energy release rate is defined as the area under the traction-separation curve at any particular instant of interest [37].

Table 2. Parameters controlling the cohesive behavior at interfaces [38-41].

\begin{tabular}{cccccc}
\hline Parameters & $k_{n}, k_{s}\left(\mathrm{~N} / \mathrm{mm}^{3}\right)$ & $\sigma_{n}^{0}(\mathrm{MPa})$ & $\sigma_{s}^{0}(\mathrm{MPa})$ & $G_{n}\left(\mathrm{~mJ} / \mathrm{mm}^{2}\right)$ & $G_{s}\left(\mathrm{~mJ} / \mathrm{mm}^{2}\right)$ \\
\hline TC/BC & $1.5 \times 10^{8}$ & 15 & 7.5 & 0.03 & 0.1 \\
BC/Sub & $1.5 \times 10^{8}$ & 300 & 150 & 3 & 1 \\
\hline
\end{tabular}

Two-dimensional four-node cohesive elements (COH2D4) were inserted at the TC/BC and BC/Sub interfaces, as depicted in Fig. 6b. Two-dimensional forms of Eqs. (2) and (4) were used to describe the initiation and propagation of the cohesive element. The material parameters of the cohesive elements are listed in Table 2. It is worth noting that, there are often serious convergence issues in the fracture simulation due to the softening behavior of CZM. Thus, viscous regularization options in ABAQUS were used for the cohesive elements [42]. In the numerical simulation, different thickness ratios and modulus ratios between TC and BC are obtained by changing the thickness of $\mathrm{TC}$ and modulus of $\mathrm{BC}$, respectively, in consistence with the experimentally tested samples. A series of thickness ratios of 1, 2, 3, 4 and 5 were selected for the 
parameter sensitivity analysis. For each thickness ratio, different modulus ratios were also used in simulations to identify the critical values for the interfacial fracture as well as the boundaries between the two fracture modes.

\subsection{Numerical results and discussion}

A systematic exploration of the dependence of the fracture modes on the TC-to-BC thickness ratio and modulus ratio enables us to plot a competition-mechanism map for the interfacial cracks, as shown in Fig. 8, wherein black points represent the simulation results of the boundary between the two failure modes. The error bars are associated with numerical considerations, and quantify the uncertainty with which the boundary of the transition can be determined, i.e. in the uncertain regime covered by error bars, two failure modes exist simultaneously. The black line in Fig. 8 is obtained by fitting the simulation points, and divides the parameter space into two regimes. As might be intuitively expected, the map shows that failure at TC/BC interface is promoted by high values of both thickness ratio and modulus ratio. Conversely, delamination from $\mathrm{BC} / \mathrm{Sub}$ interface appears to be caused by low values of these two ratios. This trend of fracture characteristic is consistent with the study on double-ceramic-layer TBCs conducted by Xu et al. [7], finding that the large thickness ratio between top layer (TC1) and second layer (TC2) leads to delamination at $\mathrm{TC} 1 / \mathrm{TC} 2$ interface, while the small thickness ratio results in delamination at $\mathrm{TC} 2 / \mathrm{BC}$ interface. Furthermore, the failure mode is sensitive to thickness ratio at larger values of the modulus ratio, but an insensitivity to thickness ratio is found at smaller values of the modulus ratio. The shape of the failure mode boundary, i.e. the modulus ratio tends to be a constant when the thickness ratio having relatively large values further increases, suggests that there may be an asymptotic value of about 2.75 for very low modulus ratio (see the dotted red line in Fig. 8), below which failure at $\mathrm{BC} / \mathrm{Sub}$ interface always occurs. By contrast, there is no indication of the existence of an asymptotic thickness ratio. The competition-mechanism map provides the feasibility to clearly distinguish the respective effect of TC-to-BC thickness ratio and modulus ratio on the fracture mode, which has not been realized in previous researches [7, 14]. 


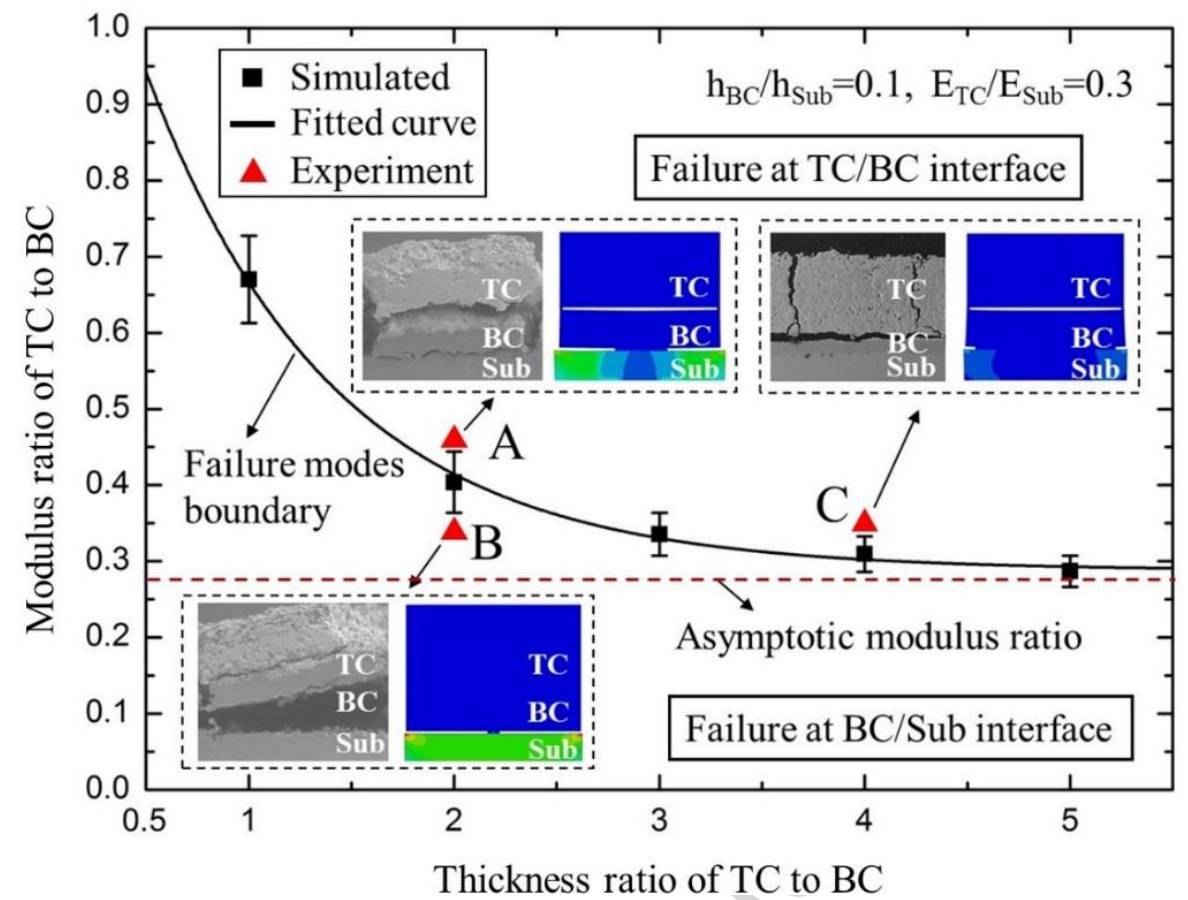

Fig. 8. Competition map showing the effects of thickness ratio and modulus ratio of TC to BC on the failure modes. The values of the $\mathrm{h}_{\mathrm{BC}} / \mathrm{h}_{\mathrm{Sub}}$ and $\mathrm{E}_{\mathrm{TC}} / \mathrm{E}_{\mathrm{Sub}}$ for this plot are 0.1 and 0.3 , respectively.

The experiment results are also included in Fig. 8, with three cases considered according to three kinds of TBCs used in experiments (see details in Section 3). The Young's modulus of BC sprayed by APS and HVOF used in the calculations is $90 \mathrm{GPa}$ and $125 \mathrm{GPa}[14,43]$, respectively, and the Poisson's ratio is 0.3 . The red point A refers to the TBCs with $300 \mu \mathrm{m}$ TC and $150 \mu \mathrm{m} \mathrm{BC}$, in which the BC is sprayed by APS (Fig. 3a). In this case, the numerical result of fracture mode agrees well with the experimental result, i.e. interfacial cracks initiated and propagated at both two interfaces, but eventually the TBCs fractured at $\mathrm{TC} / \mathrm{BC}$ interface. The comparison of the crack pattern is shown in the dashed box in Fig. 8. The red point B refers to the TBCs with $300 \mu \mathrm{m}$ TC and $150 \mu \mathrm{m} \mathrm{BC}$, in which the BC is deposited by HVOF (Fig. 3b and Fig. 4b). Although there is little difference between the two experimental results in Fig. $3 b$ and Fig. 4b that TC/BC interfacial crack exists in Fig. $3 \mathrm{~b}$ and not in Fig. 4b, the final delamination always occurs at BC/Sub interface. The little difference is due to the initial defects in TBCs samples, which cannot be accurately controlled in the spraying process. Simulation result is also consistent with experiment, i.e. the coating peeled off from $\mathrm{BC} / \mathrm{Sub}$ interface. Excellent agreement between the simulation and experiment is also found for the red point $\mathrm{C}$, as shown in Fig. 4a, which represents the TBCs with $600 \mu \mathrm{m}$ TC and $150 \mu \mathrm{m} \mathrm{BC} \mathrm{(HVOF} \mathrm{sprayed).}$ 
The finite element analysis indicates that a distinctive fracture mode can be induced in TBCs with a given parameter group of thickness ratio and modulus ratio. It is well-known that more cracks imply more energy dissipation, and also higher load required to produce the cracks. This would lead to an important consideration in delaying the delamination of TBCs, i.e. both TC/BC and $\mathrm{BC} / \mathrm{Sub}$ interfacial cracks could be triggered in order to dissipate more external energies and achieve a better bending-resistance. It should be noted that, however, some parameters other than the thickness ratio and modulus ratio considered here, may also affect the competition mechanism, which requires further study in the future.

\section{Conclusion}

This paper focuses on the competition mechanism of interfacial cracks in thermal barrier coating system (TBCs). The competition mechanism is elucidated by experimental and numerical investigations, and the finding provides a guidance to optimize the design of coatings in gas turbines and other applications involving mechanical loadings. The main conclusions are summarized as follows.

(1) The effects of thickness ratio and modulus ratio between top coat and bond coat on the failure modes were observed and characterized in a series of in-situ three-point bending experiments. Two typical failure modes were identified, i.e. delamination occurs at top-coat/bond-coat interface for TBCs with low-modulus bond coat and thicker top coat, while at bond-coat/substrate interface for TBCs with high-modulus bond coat and thinner top coat.

(2) The fracture process was also recorded and a typical competition phenomenon between different interfacial cracks in TBCs was captured for the first time. The experimental observation directly shows the existence of the competition between two interfacial cracks. The differences in modulus ratio and thickness ratio between top coat and bond coat are regarded as the main factors affecting the mechanism.

(3) Numerical studies based on the cohesive zone model were conducted to investigate the effects of modulus ratio and thickness ratio on the failure modes via a parameter sensitivity analysis. Failure map was obtained, and critical parameters defining the boundary of two failure regimes were determined. The numerical results are in good 
agreement with the experiments, and furthermore, they show that there exists an asymptotic value of low modulus ratio associated with the BC/Sub interfacial cracks. However, no similar asymptotic value was found for thickness ratio.

(4) It is advised that the occurrence of both $\mathrm{TC} / \mathrm{BC}$ and $\mathrm{BC} / \mathrm{Sub}$ interfacial cracks is preferred, as more energy dissipation and better bending-resistance can be achieved. In a design point of view, proper parameter groups of thickness ratio and modulus ratio can be chosen to ensure the occurrence of two kinds of interfacial cracks. Therefore, the finding on the competition mechanism might be valuable in the failure mode prediction and durability design of TBCs.

\section{Acknowledgement}

This work was supported by China 973 Program (2013CB035700) and National Natural Science Foundation of China (11472204 and U1530259)

\section{References}

[1] V. Kumar, K. Balasubramanian, Progress update on failure mechanisms of advanced thermal barrier coatings: A review, Progress in Organic Coatings, 90 (2016) 54-82.

[2] T. Sadowski, P. Golewski, Loadings in thermal barrier coatings of jet engine turbine blades, Springer Singapore, 2 (2016) 5-10.

[3] N. Nayebpashaee, S.H. Seyedein, M.R. Aboutalebi, H. Sarpoolaky, S.M.M. Hadavi, Finite element simulation of residual stress and failure mechanism in plasma sprayed thermal barrier coatings using actual microstructure as the representative volume, Surface and Coatings Technology, 291 (2016) $103-114$

[4] W. Fan, Y. Bai, Review of suspension and solution precursor plasma sprayed thermal barrier coatings, Ceramics International, 42 (2016) 14299-14312.

[5] Y.C. Zhou, T. Tonomori, A. Yoshida, L. Liu, G. Bignall, T. Hashida, Fracture characteristics of thermal barrier coatings after tensile and bending tests, Surface and Coatings Technology, 157 (2002) $118-127$

[6] X.L. Fan, R. Xu, W.X. Zhang, T.J. Wang, Effect of periodic surface cracks on the interfacial fracture of thermal barrier coating system, Applied Surface Science, 258 (2012) 9816-9823.

[7] R. Xu, X.L. Fan, T.J. Wang, Mechanisms governing the interfacial delamination of thermal 
barrier coating system with double ceramic layers, Applied Surface Science, 370 (2016) 394-402.

[8] X.Y. Xie, H.B. Guo, S.K. Gong, H.B. Xu, Thermal cycling behavior and failure mechanism of $\mathrm{LaTi}_{2} \mathrm{Al}_{9} \mathrm{O}_{19} / \mathrm{YSZ}$ thermal barrier coatings exposed to gas flame, Surface and Coatings Technology, 205 (2011) 4291-4298.

[9] L. Wang, D.C. Li, J.S. Yang, F. Shao, X.H. Zhong, H.Y. Zhao, K. Yang, S.Y. Tao, Y. Wang, Modeling of thermal properties and failure of thermal barrier coatings with the use of finite element methods: A review, Journal of the European Ceramic Society, 36 (2016) 1313-1331.

[10] F. Mauget, F. Hamon, M. Morisset, J. Cormier, F. Riallant, J. Mendez, Damage mechanisms in an EB-PVD thermal barrier coating system during TMF and TGMF testing conditions under combustion environment, International Journal of Fatigue, 99 (2016) 225-234.

[11] A.R. Krause, H.F. Garces, G. Dwivedi, A.L. Ortiz, S. Sampath, N.P. Padture, Calcia-magnesia-alumino-silicate (CMAS)-induced degradation and failure of air plasma sprayed yttria-stabilized zirconia thermal barrier coatings, Acta Materialia, 105 (2016) 355-366.

[12] F. Erdogan, M. Ozturk, Periodic cracking of functionally graded coatings, International Journal of Engineering Science, 33 (1995) 2179-2195.

[13] G.W. Schulze, F. Erdogan, Periodic cracking of elastic coatings, International Journal of Solids and Structures, 35 (1998) 3615-3634.

[14] Z.B. Chen, Z.G. Wang, S.J. Zhu, Tensile fracture behavior of thermal barrier coatings on superalloy, Surface and Coatings Technology, 205 (2011) 3931-3938.

[15] X.L. Fan, W.X. Zhang, T.J. Wang, G.W. Liu, J.H. Zhang, Investigation on periodic cracking of elastic film/substrate system by the extended finite element method, Applied Surface Science, 257 (2011) 6718-6724.

[16] X.L. Fan, W.X. Zhang, T.J. Wang, Q. Sun, The effect of thermally grown oxide on multiple surface cracking in air plasma sprayed thermal barrier coating system, Surface and Coatings Technology, 208 (2012) 7-13.

[17] X.F. Fang, G.B. Zhang, X. Feng, Performance of TBCs system due to the different thicknesses of top ceramic layer, Ceramics International, 41 (2015) 2840-2846.

[18] X.J. Chen, Y. You, Weight functions for multiple edge cracks in a coating, Engineering Fracture Mechanics, 116 (2014) 31-40.

[19] C. Bumgardner, X.D. Li, Unveiling ultra-high temperature wear and indentation damage 
mechanisms of thermal barrier coatings, Journal of The Minerals, Metals and Materials Society, 67 (2015) 2921-2933.

[20] Y.L. Sun, W.X. Zhang, J.G. Li, T.J. Wang, Local stress around cap-like portions of anisotropically and nonuniformly grown oxide layer in thermal barrier coating system, Journal of Materials Science, 48 (2013) 5962-5982.

[21] C. Bumgardner, B. Croom, X.D. Li, High-temperature delamination mechanisms of thermal barrier coatings: in-situ digital image correlation and finite element analyses, Acta Materialia, 128 (2017) 54-63.

[22] D.A. Anazi, M.S.J. Hashmi, B.S. Yilbas, Three-point bend testing of HVOF AMDRY 9954 coating on Ti-6Al-4V alloy, Journal of Materials Processing Technology, 174 (2006) 204-210.

[23] W.Z. Li, Y. Yao, Y.Q. Li, J.B. Li, J. Gong, C. Sun, X. Jiang, Damage behavior of the NiCrAlY coating systems with or without barrier layer during three-point bending, Materials Science and Engineering A, 512 (2009) 117-125.

[24] X.N. Li, L.H. Liang, J.J. Xie, L. Chen, Y.G. Wei, Thickness-dependent fracture characteristics of ceramic coatings bonded on the alloy substrates, Surface and Coatings Technology, 258 (2014) 1039-1047.

[25] J. Cook, J.E. Gordon, C.C. Evans, D.M. Marsh, A mechanism for the control of crack propagation in all-brittle systems, Proceedings of the Royal Society A, 282 (1964) 508-520.

[26] M.D. Thouless, H.C. Cao, P.A. Mataga, Delamination from surface cracks in composite materials, Journal of Materials Science, 24 (1989) 1406-1412.

[27] D. Martínez, V. Gupta, Energy criterion for crack deflection at an interface between two orthotropic media, Journal of Applied Mechanics, 59 (1992) S79-S87.

[28] M.Y. He, F.E. Heredia, D.J. Wissuchek, M.C. Shaw, A.G. Evans, The mechanics of crack growth in layered materials, Acta Metallurgica Et Materialia, 41 (1993) 1223-1228.

[29] M.Y. He, J.W. Hutchinson, Crack deflection at an interface between dissimilar elastic materials, International Journal of Solids and Structures, 31 (1994) 3443-3455.

[30] J.P. Parmigiani, M.D. Thouless, The roles of toughness and cohesive strength on crack deflection at interfaces, Journal of the Mechanics and Physics of Solids, 54 (2006) 266-287.

[31] R. Vaßen, G. Kerkhoff, D. Stöver, Development of a micromechanical life prediction model for plasma sprayed thermal barrier coatings, Materials Science and Engineering A, 303 (2001) 
100-109.

[32] H.X. Deng, H.J. Shi, H.C. Yu, B. Zhong, Determination of mixed-mode interfacial fracture toughness for thermal barrier coatings, Science China Physics, Mechanics and Astronomy, 54 (2011) $618-624$

[33] D.S. Dugdale, Yielding of steel sheets containing slits, Journal of the Mechanics and Physics of Solids, 8 (1960) 100-104.

[34] V. Tvergaard, J.W. Hutchinson, The relation between crack growth resistance and fracture process parameters in elastic-plastic solids, Journal of the Mechanics and Physics of Solids, 40 (1992) $1377-1397$.

[35] P.P. Camanho, C.G. Davila, M.F. De Moura, Numerical simulation of mixed-mode progressive delamination in composite materials, Journal of Composite Materials, 37 (2003) $1415-1438$.

[36] Y. Mi, M.A. Crisfield, G.A.O. Davies, H.B. Hellweg, Progressive delamination using interface elements, Journal of Composite Materials, 32 (1998) 1246-1272.

[37] Q.D. Yang, M.D. Thouless, Mixed-mode fracture analyses of plastically-deforming adhesive joints, International Journal of Fracture, 110 (2001) 175-187.

[38] A.G. Evans, M.Y. He, J.W. Hutchinson, Mechanics-based scaling laws for the durability of thermal barrier coatings, Progress in Materials Science, 46 (2001) 249-271.

[39] H. Qi, X. Yang, Y. Wang, Interfacial fracture toughness of APS bond coat/substrate under high temperature, International Journal of Fracture, 157 (2009) 71-80.

[40] H.X. Deng, H.J. Shi, H.C. Yu, B. Zhong, Effect of heat treatment at $900{ }^{\circ} \mathrm{C}$ on microstructural and mechanical properties of thermal barrier coatings, Surface and Coatings Technology, 205 (2011) 3621-3630.

[41] Z.H. Xu, Y.C. Yang, P. Huang, X.D. Li, Determination of interfacial properties of thermal barrier coatings by shear test and inverse finite element method, Acta Materialia, 58 (2010) 5972-5979.

[42] J.Y. Faou, G. Parry, S. Grachev, E. Barthel, How does adhesion induce the formation of telephone cord buckles?, Physical Review Letters, 108 (2012) 221-229.

[43] H.J. Jang, D.H. Park, Y.G. Jung, J.C. Jang, S.C. Choi, U. Paik, Mechanical characterization and thermal behavior of HVOF-sprayed bond coat in thermal barrier coatings (TBCs), Surface and Coatings Technology, 200 (2006) 4355-4362. 


\section{Figure captions}

Fig. 1. Schematics showing the selection of crack propagation path: (a) competition of crack deflection and penetration; (b) crack deflects along TC/BC interface and the coating peels off from $\mathrm{TC} / \mathrm{BC}$ interface (c) crack penetrates into $\mathrm{BC}$ and is arrested at $\mathrm{BC} / \mathrm{Sub}$ interface, which leads to a competition of cracks at TC/BC and $\mathrm{BC} / \mathrm{Sub}$ interfaces; (d) crack propagates at TC/BC interface; (e) crack propagates at $\mathrm{BC} / \mathrm{Sub}$ interface.

Fig. 2. (a) Schematic diagram of three-point bending setup, and (b) in-situ observation of cross-sections of TBCs sample with cracks.

Fig. 3. SEM images of group I samples, showing different fracture modes due to the different spraying methods of BC used: (a) TBCs sample with BC sprayed by APS eventually fractured at TC/BC interface (b) TBCs sample with BC sprayed by HVOF eventually separated from BC/Sub interface.

Fig. 4. SEM images of group II showing different fracture modes due to the different thicknesses of TC considered: (a) TBCs sample with thicker TC peeled off from TC/BC interface (b) TBCs sample with thinner TC peeled off from BC/Sub interface.

Fig. 5. SEM images showing the typical competition phenomenon between TC/BC and BC/Sub interfacial cracks in TBCs under three-point bending.

Fig. 6. (a) Illustration of the geometry of TBCs with multiple vertical cracks before the competition of interfacial cracks (b) a segment analyzed in finite element simulation.

Fig. 7. A bilinear traction-separation law used in the cohesive zone model.

Fig. 8. Competition map showing the effects of thickness ratio and modulus ratio of $\mathrm{TC}$ to $\mathrm{BC}$ on the failure modes. The values of the $\mathrm{hBC} / \mathrm{hSub}$ and ETC/ESub for this plot are 0.1 and 0.3 , respectively. 


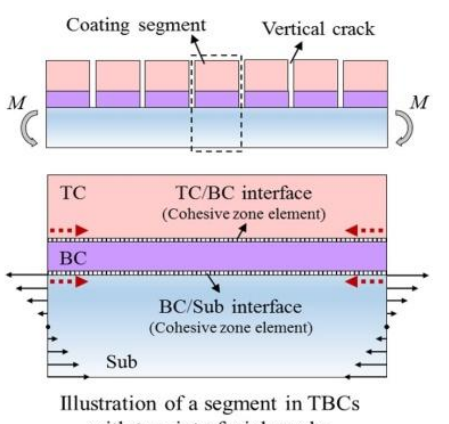

segment in TBC with two interfacial cracks

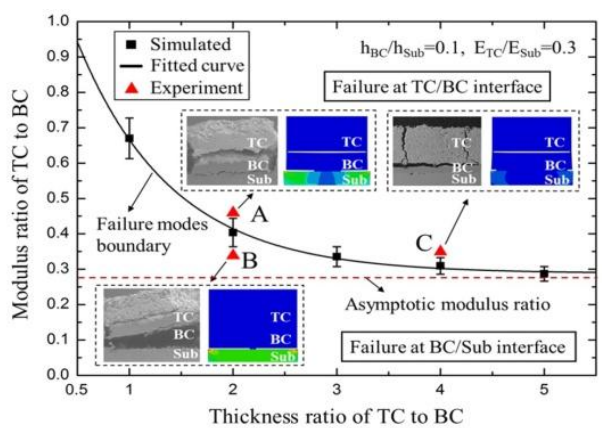

Graphical abstract 


\section{Highlights}

- Competition between interfacial cracks at top-coat/bond-coat and bond-coat/substrate interfaces in thermal barrier coatings is observed for the first time.

- Modulus ratio and thickness ratio of top coat to bond coat control the competition mechanism.

- Competition-mechanism map based on the modulus ratio and thickness ratio is established. 